\title{
Seasonal variations of ${ }^{228} \mathrm{Ra} /{ }^{226} \mathrm{Ra}$ and ${ }^{228} \mathrm{Th} /{ }^{228} \mathrm{Ra}$ ratios in surface water from the eastern East China Sea
}

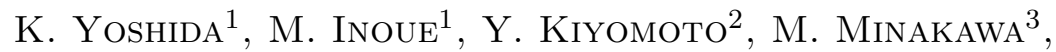 \\ H. Kofuji ${ }^{4}$, S. NAGAO $^{1}$, Y. Hamajima ${ }^{1}$ and M. YAmamoto ${ }^{1}$
}

${ }^{1}$ Institute of Nature and Environmental Technology,

Kanazawa University, Japan

${ }^{2}$ Fisheries Research Agency, Seikai National Fisheries Research Institute, Japan

${ }^{3}$ Fisheries Research Agency, National Research Institute of Fisheries Science, Japan

${ }^{4}$ Mutsu Marine Laboratory, Japan Marine Science Foundation, Aomori, Japan

\begin{abstract}
A total of 30 surface water samples were collected at 2 sites on the east side of the East China Sea (ECS) during 2008-2010, and ${ }^{226}$ Ra, ${ }^{228} \mathrm{Ra}$, and ${ }^{228} \mathrm{Th}$ activities were measured using low-background $\gamma$-spectrometry. The ${ }^{228} \mathrm{Ra} /{ }^{226} \mathrm{Ra}$ and ${ }^{228} \mathrm{Th} /{ }^{228} \mathrm{Ra}$ activity ratios of the samples exhibited notable seasonal variations $\left({ }^{228} \mathrm{Ra} /{ }^{226} \mathrm{Ra}\right.$ $\left.=0.2-3.3 ;{ }^{228} \mathrm{Th} /{ }^{228} \mathrm{Ra}=<0.1-0.4\right)$ accompanying salinity changes (31.0-34.6). These changes are hypothesized to cause the change by altering the mixing ratio of ${ }^{228}$ Ra-rich and particle-rich continental shelf water within the ECS.
\end{abstract}

\section{Introduction}

The East China Sea (ECS) is one of the largest marginal seas in the northwest Pacific Ocean with a broad continental shelf (more shallow than

This is an Open Access article distributed under the terms of the Creative Commons Attribution License 2.0, which permits unrestricted use, distribution, and reproduction in any medium, provided the original work is properly cited. 


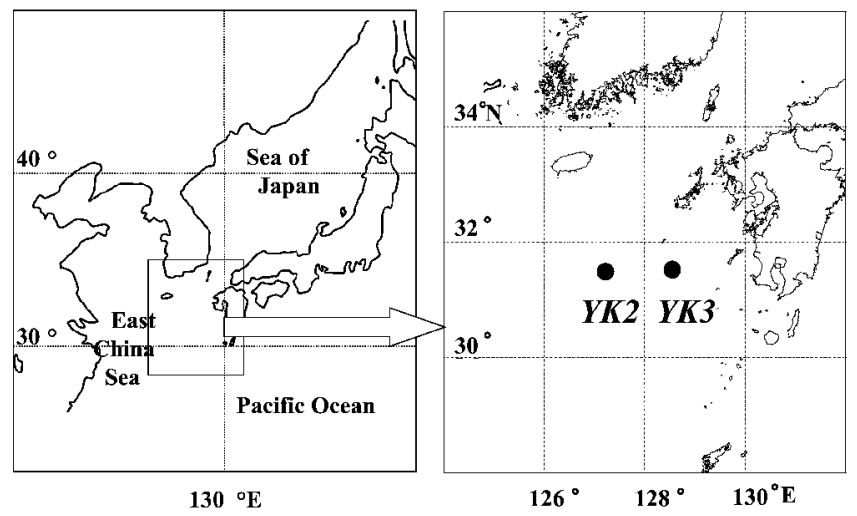

Figure 1: Sampling locations far seawater samples.

$\sim 200 \mathrm{~m})$ in the western part. To reveal geochemical cycles and hydrographic features, many researchers have studied ocean current migration patterns over the ECS using various techniques (Yanagi et al., 1997; Isobe, 2008), but clarifying water circulation characteristics in the ECS is difficult because of the region's markedly complicated seasonality (Ichikawa and Beardsley, 2002). Our previous study clarified that the ${ }^{228} \mathrm{Ra}$ (half-life $\left.\left(t_{1 / 2}\right)=5.75 \mathrm{y}\right) /{ }^{226} \mathrm{Ra}(1600 \mathrm{y})$ activity ratio of the surface water exhibited notable seasonal variation in the ECS. This is believed to be caused by a change of the mixing ratio of ${ }^{228}$ Ra-rich continental shelf water and ${ }^{228}$ Ra-poor Kuroshio water (Inoue et al., 2010). The ECS is an area of high productivity and particle scavenging (Iseki et al., 2003). Because of the particle-reactive property of thorium isotopes, the ${ }^{228} \mathrm{Th}(1.91 \mathrm{y})$ activity of seawater and the extent of its disequilibrium with its soluble parent ${ }^{228} \mathrm{Ra}$ $\left({ }^{228} \mathrm{Th} /{ }^{228} \mathrm{Ra}\right.$ ratio) have often been utilized to estimate scavenging from seawater (Bacon, 2004). In the present study, we examined the seasonal change in the ${ }^{228} \mathrm{Th} /{ }^{228} \mathrm{Ra}$ ratio of surface waters in the ECS together with that of ${ }^{228} \mathrm{Ra} /{ }^{226} \mathrm{Ra}$, and assessed seasonal circulation of water and particles.

\section{Samples and experimental method}

Seawater sampling locations on the east side of the ECS are shown in Fig. 1. A total of 30 surface water samples $(\sim 20 \mathrm{~L})$ were collected from 2 sites ( $Y K 2,31^{\circ} 45^{\prime} \mathrm{N}-127^{\circ} 15^{\prime} \mathrm{E}, 125 \mathrm{~m} ; Y K 3,31^{\circ} 45^{\prime} \mathrm{N}-128^{\circ} 45^{\prime} \mathrm{E}, 762 \mathrm{~m}$ ) in $2-4$ months interval during the Yoko Maru and Soyo Maru expeditions in 20082010. Detailed explanations of these experimental procedures were pre- 
sented elsewhere (Nakano et al., 2008). Briefly, the least Ra-contaminated $\mathrm{Ba}\left(0.7 \mathrm{mBq} / \mathrm{g}-\mathrm{Ba}\right.$ for ${ }^{226} \mathrm{Ra} ; 0.2 \mathrm{mBq} / \mathrm{g}-\mathrm{Ba}$ for $\left.{ }^{228} \mathrm{Ra}\right)$ and Fe carriers were added to unfiltered water, and $\mathrm{BaSO}_{4}$ and $\mathrm{Fe}(\mathrm{OH})_{3}$ were precipitated with radium and thorium isotopes. Low-background $\gamma$-spectrometry was performed using Ge-detectors located at the Ogoya Underground Laboratory, Japan (Hamajima and Komura, 2004). The yields of radium isotopes and ${ }^{228} \mathrm{Th}$ were tentatively estimated to be $85 \%$ and $90 \%$.

\section{Results and discussion}

\subsection{Seasonal variations of ${ }^{228} \mathrm{Ra}$ activity and ${ }^{228} \mathrm{Ra} /{ }^{226} \mathrm{Ra}$ ratio}

Seasonal Variations of ${ }^{228} \mathrm{Ra}$ activity and ${ }^{228} \mathrm{Ra} /{ }^{226} \mathrm{Ra}$ ratio are presented in Fig. 2. The ${ }^{228} \mathrm{Ra} /{ }^{226} \mathrm{Ra}$ ratio of waters exhibits a wide variation (0.2-3.3), mainly resulting from variation in the activity of short-lived ${ }^{228} \mathrm{Ra}$ (0.2-7.4 $\left.\mathrm{mBq} \mathrm{L}^{-1}\right)$ supplied from the shallow continental shelf (Fig. 2). In winter and spring, the ${ }^{228} \mathrm{Ra} /{ }^{226} \mathrm{Ra}$ ratios at $Y K 2$ and $Y K 3$ are similar to that of Kuroshio water. In summer, ${ }^{228}$ Ra-rich shelf water appears to be brought to the east side, and the ${ }^{228} \mathrm{Ra} /{ }^{226} \mathrm{Ra}$ ratios at $Y K 2$ and $Y K 3$ reach higher levels, reflecting large contributions of shelf water. The ${ }^{228} \mathrm{Ra} /{ }^{226} \mathrm{Ra}$

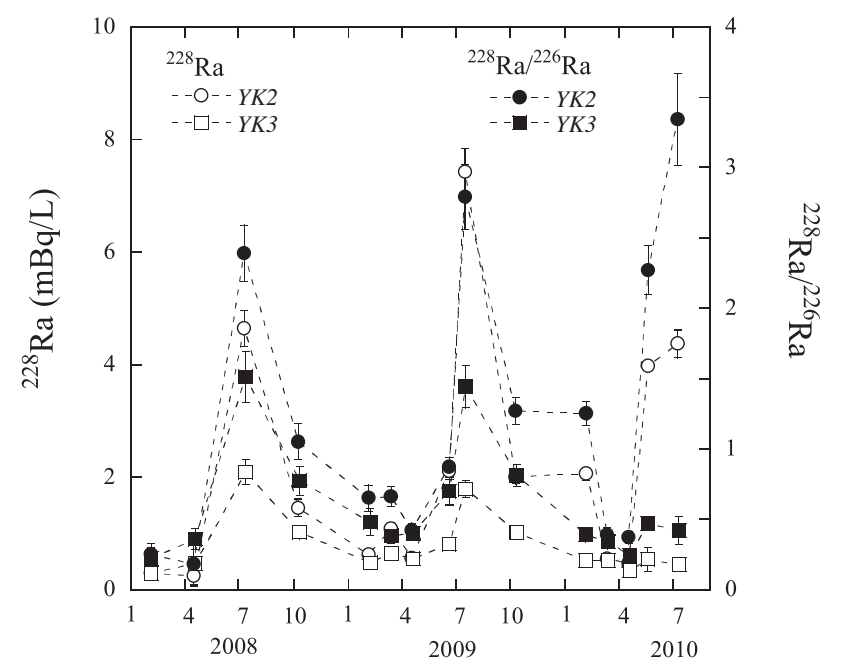

Figure 2: Seasonal variations of ${ }^{228} \mathrm{Ra}$ activity and ${ }^{228} \mathrm{Ra} /{ }^{226} \mathrm{Ra}$ ratio in surface waters of the ECS (sites YK2 and YK3). Data in 2008 are from Inoue et al. (2010). 


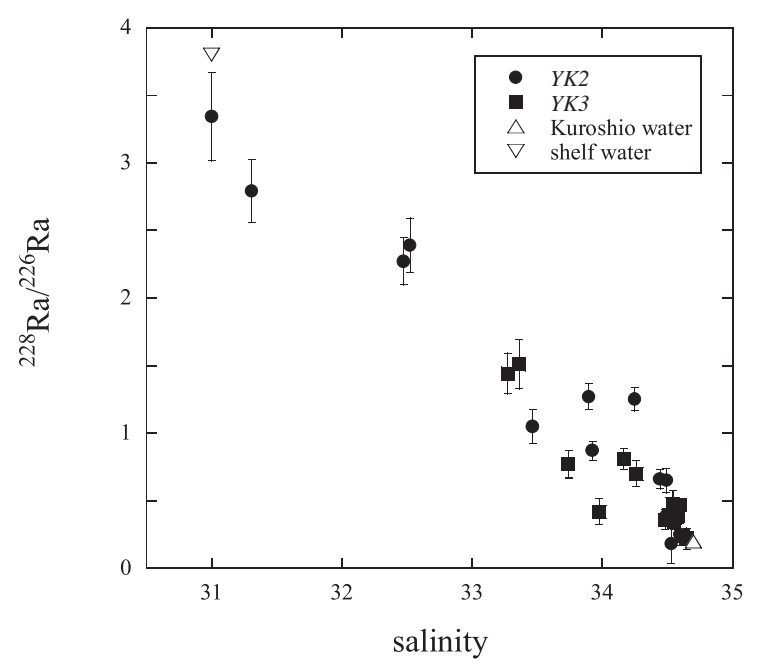

Figure 3: ${ }^{228} \mathrm{Ra} /{ }^{226} \mathrm{Ra}$ ratio vs salinity in surface waters of sites $Y K 2$ and $Y K 3$.

ratio of water in the continental side (site $Y K 2$ ) is evidently higher compared with that in Japan side (site $Y K 3$ ). On the other hand, annual variations of ${ }^{228} \mathrm{Ra} /{ }^{226} \mathrm{Ra}$ ratio are also observed during this period (e.g., high ${ }^{228} \mathrm{Ra} /{ }^{226} \mathrm{Ra}$ ratio at $Y K 2$ and markedly low ratio at $Y K 3$ in July 2010), which reflects the annual difference of the mixing pattern of shelf water.

The ${ }^{228} \mathrm{Ra} /{ }^{226} \mathrm{Ra}$ ratio is plotted against salinity in Fig. 3. The continental shelf water in the ECS exhibits a markedly higher ${ }^{228} \mathrm{Ra} /{ }^{226} \mathrm{Ra}$ ratio and lower salinity $\left({ }^{228} \mathrm{Ra} /{ }^{226} \mathrm{Ra}, \sim 3.8\right.$; salinity, $\left.\sim 31\right)$ than water from the Kuroshio-dominated area $(\sim 0.2 ; \sim 34.7)$ (Nozaki et al., 1989). As shown in Fig. 3, the ${ }^{228} \mathrm{Ra} /{ }^{226} \mathrm{Ra}$ ratio in $Y K$ waters is fundamentally within the range between values observed in the Kuroshio and shelf waters. The wide range of the ${ }^{228} \mathrm{Ra} /{ }^{226} \mathrm{Ra}$ ratio at $Y K$ is explained by the seasonal and lateral variations of the mixing ratio of the shelf water.

\subsection{Seasonal variations of ${ }^{228} \mathrm{Th}$ activity and ${ }^{228} \mathrm{Th} /{ }^{228} \mathrm{Ra}$ ratio}

The seasonal variation of ${ }^{228} \mathrm{Th}$ activity is compared to that of ${ }^{228} \mathrm{Th} /{ }^{228} \mathrm{Ra}$ ratio in Fig. 4. The ${ }^{228} \mathrm{Th}$ activity is markedly high in summer $\left(0.5 \mathrm{mBq} \mathrm{L}{ }^{-1}\right.$ at $Y K 2)$, which is due to the high activity of the parent nuclides ${ }^{228} \mathrm{Ra}$. In Fig. 5, the ${ }^{228} \mathrm{Th} /{ }^{228} \mathrm{Ra}$ ratio at the ECS surface is plotted against salinity. The water with high ${ }^{228} \mathrm{Th}$ activity and low salinity $(<34)$ exhibits 


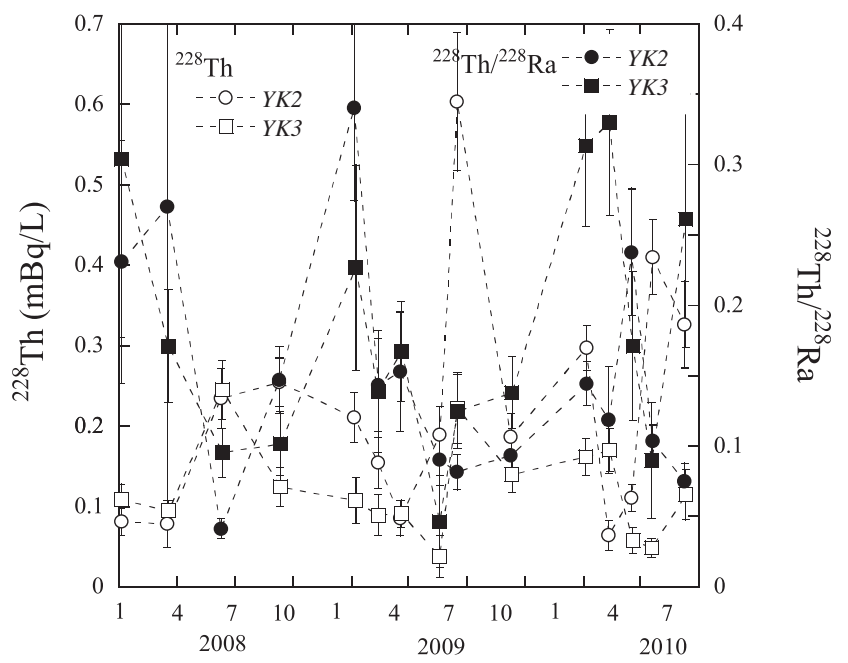

Figure 4: Seasonal variations of ${ }^{228} \mathrm{Th}$ activity and ${ }^{228} \mathrm{Th} /{ }^{228} \mathrm{Ra}$ ratio in surface waters of $Y K 2$ and $Y K 3$.

a lower ${ }^{228} \mathrm{Th} /{ }^{228} \mathrm{Ra}$ ratio (0.05-0.15) relative to high salinity (34.0-34.6) Kuroshio-dominated water $\left({ }^{228} \mathrm{Th} /{ }^{228} \mathrm{Ra}=0.15-0.35\right)$. Reactive nuclides $\left({ }^{234} \mathrm{Th},{ }^{210} \mathrm{~Pb},{ }^{210} \mathrm{Po}\right.$, and $\left.{ }^{10} \mathrm{Be}\right)$ in the surface water on the shelf are much lower than that on the Kuroshio area, being due to the vigorous scavenging

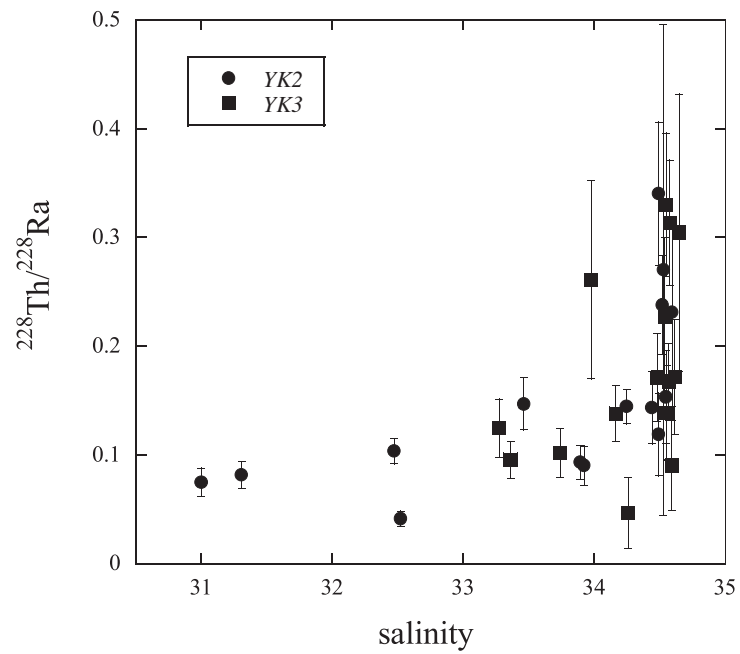

Figure 5: ${ }^{228} \mathrm{Th} /{ }^{228} \mathrm{Ra}$ ratio vs salinity in surface waters of $Y K 2$ and $Y K 3$. Large deviation of ${ }^{228} \mathrm{Th} /{ }^{228} \mathrm{Ra}$ in the high salinity water is due to large statistical errors of low ${ }^{228} \mathrm{Ra}$ and ${ }^{228} \mathrm{Th}$ activities. 
into sediments on the shelf area (Nozaki et al., 1991; Aono and Yamada, 1999; Yang et al., 2003). The lower ${ }^{228} \mathrm{Th} /{ }^{228} \mathrm{Ra}$ ratio of the shelf water in summer is considered to be caused by the removal of ${ }^{228} \mathrm{Th}$ by the scavenging (Yamada and Aono, 2006).

In order to elucidate the variation of ${ }^{228} \mathrm{Th} /{ }^{228} \mathrm{Ra}$ ratio, further experimentation and study (fine-resolution lateral and vertical measurements of these nuclides within the ECS) are needed.

\section{Acknowledgements}

We are indebted to the researchers, captain and crew of the R/Vs Yoko Maru and Soyo Maru for their assistance during sampling. This study was supported in partly by the Sasagawa Scientific Research Grant from The Japan Science Society (K. Yoshida) and a Grant-in-Aid for Scientific Research No. 21510011 from the Ministry of Education, Culture, Sports, Science and Technology of Japan (M. Inoue).

\section{References}

Bacon M. P., in Marine Radioactivity, edited by Livingston H. D. (Elsevier) 2004, pp. 139-165.

Hamajima Y. and Komura K., Appl. Radiat. Isot. 61 (2004) 179.

Ichikawa H. and Beardsley R. C., J. Oceanogr. 58 (2002) 77.

Inoue M., Nakano Y., Kiyomoto Y., Kofuji H., Hamajima Y. and Yamamoto M., J. Oceanogr. 66 (2010) 425.

Iseki K., Okamura K. and Kiyomoto Y., Deep-Sea Res. II 50 (2003) 457.

Isobe A., J. Oceanogr. 64 (2008) 569.

Nakano Y., Inoue M. and Komura K., J. Oceanogr. 64 (2008) 713.

Nozaki Y., Kasemsupaya V. and Tsubota H., Geophys. Res. Lett. 16 (1989) 1297.

Nozaki Y., Tsubota H., Kasemsupaya V., Yashima M. and Ikuta N., Geochim. Cosmochim. Acta 55 (1991) 1265.

Yamada M. and Aono T., Mar. Geol. 227 (2006) 1. 
ER2010

Yanagi T., Morimoto A. and Ichikawa K., Continental Shelf Res. 17 (1997) 655 .

Yang Y.-L., Kusakabe M. and Southon J. R., Deep-Sea Res. II 50 (2003) 339. 